nurses. The rate of transmission was between 6 and $10 \%$ to 158 newborns cared for in such a way that organisms from infant carriers could be transmitted to them only via the airborne route. In contrast, 126 infants who were handled by nurses who also handled the neighbouring carrier babies with little or no handwashing exhibited a $43 \%$ rate of acquisition of the carrier strains. A careful hexachlorophane wash of the hands of the nurses who cared for the carriers decreased the transmission rate to $14 \%$. The carrier strains were often recovered from settling-plates exposed throughout the special nursery.

It is concluded that under ordinary circumstances airborne organisms probably account for only a small proportion of staphylococcal transmission in the nursery, and that efficient handwashing techniques can reduce staphylococcal spread appreciably.
This investigation was conducted under the sponsorship of the Commission on Streptococcal and Staphylococcal Diseases, Armed Forces Epidemiological Board, and was supported by the Office of the Surgeon General, Department of the Army, Washington, D.C., and United States Public Health Service Training Grant No. 2E-180.

The Department of Nursing of Cleveland Metropolitan General Hospital co-operated in this investigation, and Mrs. Dorothy Simon and Miss Barbara Brady provided technical assistance. Mrs. Donna Hines, R.N., supervised the special nurses.

\section{REFERENCES}

Blair, J. E., and Carr, M. (1960). f. Lab. clin. Med., 55, 650. Mortimer, E. A., jun., Lipsitz, P. J., Wolinsky, E., Gonzaga, A., and Rammelkamp, C. H., jun. (1962). Amer. F. Dis. Child. 104, 289. Wolinsky, E., Lipsitz, P. J., Mortimer, E. A., jun., and Rammelkamp. C. H., jun. (1960). Lancet, 2, 620 .

\title{
New Treatment of Some Chronic Tension States
}

\author{
WILLIAM SARGANT,* M.B., F.R.C.P., D.P.M. ; C. J. S. WALTER,* M.B., B.S., D.P.M. \\ NICHOLAS WRIGHT,* M.B., M.R.C.P., D.P.M.
}

Brit. med. F., 1966, 1, 322-324

Birley (1964) reported a follow-up study, which he had started some years previously, of over a hundred patients given modified leucotomy on the advice of one of us (W.S.) at either St. Thomas's or Belmont Hospital during the past 15 years. One of the most interesting and unexpected findings was the frequency with which clear-cut depressive episodes had occurred months or years after the leucotomy. This was especially the case in those patients who had been operated on with the diagnosis of a "chronic tension state" in a good previous personality. These unexpected attacks of depression following leucotomy had also mostly then responded to treatment with antidepressant drugs and/or electric convulsion treatment (E.C.T.). The conclusion therefore seemed undeniable that in these patients there had often been a marked depressive component to the total picture, which had been overlooked prior to leucotomy. Because of this, E.C.T. had often been inadequately given, or even not used at all, for fear of aggravating the chronic tension state thought to be present.

Many such chronically tense and anxious patients are always being sent to the Department of Psychological Medicine at St. Thomas's Hospital for a final decision on whether or not a modified leucotomy would help them. Generally, however, the psychiatrists referring these patients have tried most other treatments before finally deciding to do so.

Birley's follow-up finding led to a serious reappraisal of our previous indications for leucotomy (Sargant, 1962). And as a result, and with very few exceptions during the last few years, no case of supposed chronic anxiety neurosis, obsessional ruminative illness, or tension state occurring in patients of good previous personality has now been given the operation without a prior trial of a very thorough treatment of any possible depressive component present. Both groups of antidepressant drugs have even been given in combination; and E.C.T. also given at the same time.

- Department of Psychological Medicine, St. Thomas's Hospital, London.
In many cases a modified form of continuous narcosis was given together with the drugs and E.C.T. to make the treatment easier in some especially tense patients. And one of us (C. W.) then noticed that when this modified narcosis was used in addition to the combined antidepressants and E.C.T. the patients sometimes seemed to respond very much better than when E.C.T. and the combined antidepressant drugs were used without additional narcosis.

We now report some very encouraging and quite unexpected results when these two groups of patients are examined as a whole and also compared with one another. It has been found in fact that a large number of patients complaining of chronic tension states can now be got well after many years of illness if the previous personality is good, and without the need to resort to leucotomy in the majority of them. The number of patients helped after having been ill for years on end is quite new in our experience, and seems to constitute, if confirmed, a real advance in the treatment of a group of often seemingly hopeless illnesses. And patients given narcosis combined with E.C.T. and the antidepressant drugs have been found to do surprisingly better than those given E.C.T. and the drugs alone.

\section{Patients Treated}

This paper examines a group of 73 consecutive patients suffering from long-standing " tension states" in good previous personalities, mostly referred to St. Thomas's by other psychiatrists during 1962-4 for a final decision about leucotomy. Cases of obvious endogenous and agitated depression, recurrent endogenous depression, gross hysteria, obsessional compulsive illness, and chronic personality disorder have all been excluded. The patients under discussion complained preponderantly of symptoms of prolonged tension or anxiety (see Table III). Depression was also complained of by $64 \%$ of patients. Often the illness was complicated by obsessional thoughts and even hysterical 
behaviour. But all the patients had been of good previous personality before their illness. This was shown by an absence of pathological anxiety prior to the illness, the presence of conscientiousness, good basic drive, and a proved capacity for environmental adjustment. When well they had been able to cope with life adequately and normally, but had not been able to do so ever since the onset of their long neurotic illnesses.

The results are presented for the group as a whole, and a comparison is also made between the two subgroups-one that received narcosis with combined drugs and E.C.T., and the other that did not do so, but had combined drugs and E.C.T. alone. Fortunately, but quite accidentally, the two subgroups agree very closely in age and sex distribution (Table I), and also in previous treatments and hospital admissions (Table II). In Table III the symptoms complained of by both subgroups are given as a whole, and tension is the commonest symptom. Table IV shows the duration of illness in the two subgroups. It will be seen that no fewer than 25 patients out of the 73 had had illnesses for over 10 years, and the average duration of all the illnesses was eight years, despite the patients' good previous personalities.

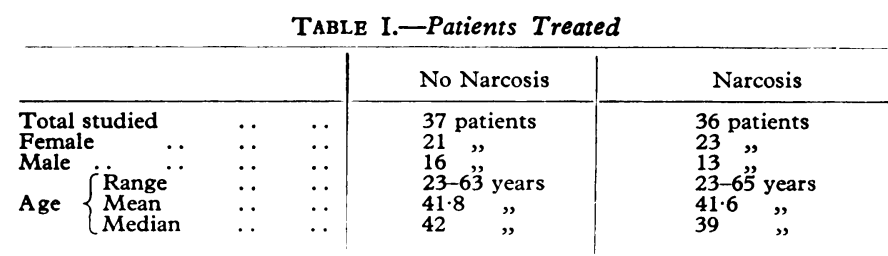

\begin{tabular}{|c|c|c|c|c|}
\hline & & & No Narcosis & Narcosis \\
\hline $\begin{array}{l}\text { Hospital } \\
\text { admissions } \\
\text { Leucotomy } \\
\text { E.C.T. } \\
\text { Analysis } \\
\text { Group therapy }\end{array}$ & $\begin{array}{l}\left\{\begin{array}{l}0 \\
1 \\
2-5 \\
6+\ldots\end{array}\right. \\
\quad \quad \cdots \\
\quad \cdots\end{array}$ & $\begin{array}{l}\because \\
\because \\
\because \\
\cdots \\
\cdots\end{array}$ & 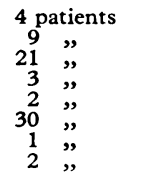 & 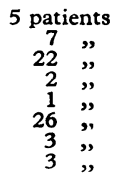 \\
\hline
\end{tabular}

TABLE III.-Symptoms Complained of by Patients

\begin{tabular}{|c|c|c|c|c|}
\hline & & No Narcosis & Narcosis & Total (\%) \\
\hline $\begin{array}{l}\text { Tension } \\
\text { Depression } \\
\text { Phobic fears and panics } \\
\text { Anxiety } \\
\text { Somatic equivalents } \\
\text { Habituation to drugs }\end{array}$ & $\begin{array}{l}\because \\
\because \\
\because \\
\therefore \\
\end{array}$ & $\begin{array}{r}28 \\
24 \\
13 \\
21 \\
5 \\
3\end{array}$ & $\begin{array}{r}30 \\
23 \\
17 \\
11 \\
4 \\
5\end{array}$ & $\begin{array}{l}79 \cdot 5 \\
64 \cdot 4 \\
41 \cdot 1 \\
43 \cdot 8 \\
12 \cdot 3 \\
11 \cdot 0\end{array}$ \\
\hline
\end{tabular}

TABLE IV.-Length of Illness

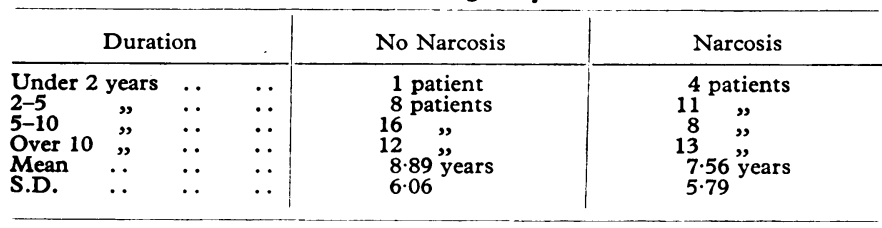

\section{Details of Treatment}

Sixty-six patients received combined antidepressant drugs -35 in the narcosis group and 31 in the non-narcosis group. Marsilid (iproniazid) and Tryptizol (amitriptyline hydrochloride) were used together in 51 patients, Tryptizol and Marplan in 5, Tofranil (imipramine hydrochloride) and Marsilid in a further five patients, and Nardil (phenelzine hydrogen sulphate) with both Tryptizol and Tofranil were also used. When necessary the doses were adjusted for each patient. But initially the dose generally given was Marsilid 75-150 mg., Nardil 45 mg., or Marplan (isocarboxazid) 30 mg. daily, and Tryptizol $75-150 \mathrm{mg}$. or Tofranil $150 \mathrm{mg}$. daily.
In a follow-up study of this nature it is difficult to detail all the minor side-effects met with, such as tremor, giddiness, and constipation. But a good record of any serious sideeffects is available. No cases of jaundice occurred despite all the Marsilid used. There were also no collapses or hyperpyrexial episodes that are reported-we believe wrongly-to follow the use of combined drugs in proper dosage by mouth. Most patients seemed to thrive on the combination, and in fact 12 patients gained over half a stone $(3.2 \mathrm{~kg}$.) over their normal weight during treatment. Oedema of the ankle and difficulty in passing urine occurred, each in one patient only, both clearing up on reducing the dose of Marsilid. The dosage of combined antidepressant drugs was adjusted when improvement had occurred, and patients were generally discharged from hospital on maintenance doses of both these drugs.

E.C.T. was also given at the same time as the drugs to 65 of the 73 patients; an average of 11 E.C.T.s were given in both groups. However, in some patients over 20 treatments were needed and in others very few. A further 13 patients received modified insulin treatments, generally before or after treatment-six were in the narcosis group and seven in the other.

The continuous narcosis, of a light and safe depth, was given mainly by means of large doses of Largactil (chlorpromazine hydrochloride), and small amounts of hypnotics such as chloral, Sodium Amytal (amylobarbitone sodium), or Melsedin (methaqualone hydrochloride) (Sargant and Slater, 1963), were also given to 36 of the 73 patients while they were receiving the combined antidepressant drugs and E.C.T. The dose of the drugs was adjusted in each case, but varied between Largactil 100-300 mg. four- to six-hourly, Sodium Amytal $1 \frac{1}{2}-3$ gr. (0.1-0.2 g.) six-hourly, chloral $30-45$ gr. (2-3 g.) six-hourly, and Melsedin 150-300 mg. six-hourly. Initially sleep was induced with the higher doses quoted, and patients slept for up to 20 hours a day. Three full meals a day had to be taken, and if necessary the patients were hand-fed by the nurse. It is also most important to keep fluid intake above $100 \mathrm{oz}$. (2,840 ml.) a day. The duration of the continuous modified narcosis in the 36 patients varied between one and seven weeks, the average being 3.9 weeks. E.C.T. was generally given once or twice a week.

As the treatment progressed the patients slept for shorter periods than the initial 20 hours. But reasonable nursing supervision is required because of the mild hypotension often induced by the drugs. No worrying complications occurred, and only once was the treatment temporarily interrupted because of an intercurrent chest infection, in a man of 56 with chronic bronchitis. At the termination of narcosis the drugs were tailed off gradually over a period of four to six days. There were no cases of withdrawal fits, which were so frequent when larger doses of barbiturates had to be used alone. The patients also continued with E.C.T. after the termination of narcosis when indicated. All through the narcosis the patients were talked to, when awake, to see if any improvement was occurring in their mental state; and the length of treatment was often determined by their response. ${ }^{1}$

When operations were done after the failure of these treatments, they were modified ones mainly confined to the lower medial quadrants of the frontal lobe. Two were done at St. Thomas's Hospital (Harvey Jackson, 1954) and 14 at Belmont Hospital (McKissock, 1959).)

\section{Results}

The first and most important finding was that of the 73 patients mostly referred for consideration of leucotomy,

1 This combined treatment can be seen being used either at Royal Waterloo Hospital or Belmont Hospital. 
and treated first in the manner described, only a mere 18 finally came to operation, despite the previous length and intractability of their illnesses. And the difference between the two subgroups having and not having narcosis was very marked. Thirteen operations out of 37 had to be done at the time when no narcosis was used, but only 3 out of 36 patients when narcosis had been given together with E.C.T. and the drugs.

The follow-up results were judged by the reduction in the severity of symptoms, the return to previous employment, and an ability to make good environmental adjustment. The patients were allotted to one of five categories (Table V). It will be seen that no fewer than 22 patients of both groups became symptom-free after very long illnesses. A further 27 patients in both groups have only minimal symptoms. The follow-up varies from five months to three years. Thirty have, however, been followed up for between 18 months and three years. Only three patients are definitely worse than they were. When we consider the hopelessness of the cases, and the variety of the psychiatrists treating them before being sent to us, the improvements seen have been remarkable, and we feel we have stumbled quite accidentally on to an often extremely effective combined method of physical treatment for certain hitherto resistant " chronic tension states" in good previous personalities. Many patients were thus saved from leucotomy.

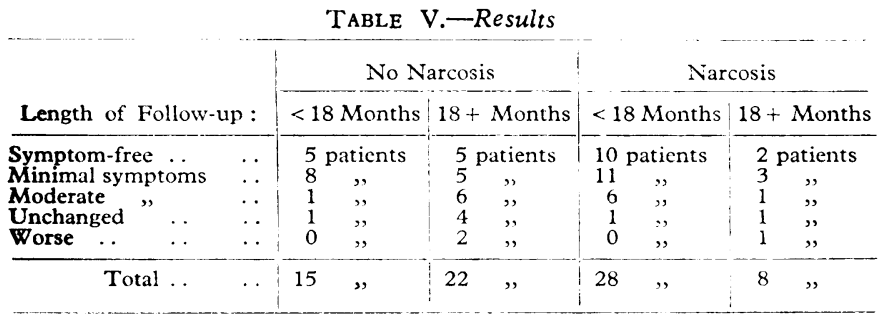

It seems certain from the figures that patients having narcosis with E.C.T. and combined antidepressive drugs do much better than those having E.C.T. and drugs alone. This may bear out the repeated insistence of Russian psychiatrists for many years past that sleep-treatment can be very valuable in treating neuroses. But our experiences with narcosis in the second world war (Sargant and Slater, 1963) did not suggest that, used alone, it would have done as much for this most resistant group of patients. The presence of a good previous personality, and not the length of the illness, also seems a sine qua non of a successful outcome. And the absence of dangerous complications in this series emphasizes how safe it really is to combine the antidepressant drugs and to use Marsilid under proper supervision and in proper dosage (Sargant, 1965); and even to give both E.C.T. and narcosis at the same time as well.

Cases of recurrent manic-depressive illness were not greatly helped by these methods. A patient may be brought out of a long attack of depression with them, but may soon relapse again. Patients with long-standing obsessive phobias and thoughts were greatly helped in this series, but not patients with predominantly obsessive compulsive rituals.

No formal or detailed psychotherapy was needed to achieve these results. Again, the finding of an effective physical approach to treatment in these chronic neuroses seems to make psychotherapy an added luxury rather than a therapeutic necessity. However, common-sense attitudes should be taken to try to make the immediate follow-up period as free from strain as possible. Maintenance drugs are also of value. During the follow-up period only four patients actually required further out-patient E.C.T., two from each group. Six patients who did not have narcosis also needed readmission, as opposed to only three of the narcosis group. Two further operations also had to be carried out in the no-narcosis group, but none in the narcosis group. The follow-up therefore provided further evidence of the value of narcosis in the total treatment set-up.

Certainly not all chronic tension states can be helped with this method. We have recently isolated a special group of patients who did not have such good previous personalities and who failed to respond to any sort of treatment except modified leucotomy. These cases can now fortunately be distinguished by special physiological testing, and will be the subject of a further paper (Kelly and Sargant, 1966).

\section{Summary}

Seventy-three consecutive patients of good previous personality are reported who were complaining of states of "chronic tension" and had been referred to St. Thomas's, mostly by other psychiatrists, for consideration of modified leucotomy.

Thirty-seven of them were first treated with combined antidepressant drugs and E.C.T., and the other 36 were given these same treatments together with continuous narcosis.

A follow-up five months to three years later showed that 49 out of 73 patients, with an average illness of eight years' duration, had become symptom-free or had only minimal residual symptoms after treatment. Only 18 of the 73 patients have subsequently had leucotomy, and it has so far been avoided in the remaining 55 , mostly by the treatments described.

It was also found that when continuous narcosis was used, combined with both groups of drugs and E.C.T., only 3 out of 36 patients needed leucotomy, as compared with 15 out of the 37 who were not given continuous narcosis together with both drugs and E.C.T.

The reason for these unexpected results, and why the narcosis group do so much better, is still uncertain. Further treatment research on many important problems raised by these findings is being carried out. But the findings themselves so far have been more than encouraging in such a difficult and intractable group of patients.

\section{REFERENCES}

Birley, J. L. T. (1964). Brit. F. Psychiat., 110, 211.

Jackson, H. (1954). f. ment. Sci., 100, 62.

Kelly and Sargant (1966). Paper in preparation.

McKissock, W. (1959). Proc. roy. Soc. Med., 53, 206.

Sargant, W. (1962). Lancet, 1, 1197.

(1965). Brit. med. F., 1, 1495.

and Dally, P. (1962). Ibid., 1, 6.

and Slater, E. (1963). An Introduction to Physical Methods of Treatment in Psychiatry, 4th ed. Livingstone, Edinburgh. 